\title{
Technique of Antroduodenectomy Without Ulcer Excision as a Safe Alternative Treatment for Bleeding Chronic Duodenal Ulcers
}

\author{
Moshe Schein
}

Published online: 14 July 2009

(c) Société Internationale de Chirurgie 2009

To the Editor,

In the article by Guinier et al., from France, the authors attribute the "discovery" of the antroduodenectomy operation, during which the stomach is anastomosed to the duodenum "over" the excluded bleeding duodenal ulcer, to Dubois in 1971 [1]. However, the fact is that exactly the same technique, for the same indication, had been described in 1968 by Dr. Erwin J. Fuerst from the United States [2]. I adopted this technique during the late 1980s [3], and since then it has proved to be an excellent option whenever a lesser, non-resective procedure, is not practical. I thank the authors for reminding the surgical community that the best way to avoid a difficult duodenal stump is to create a duodenogastrostomy. However, they should have acknowledged the earlier contribution of Dr. Fuerst. Yes, there were also a few surgical innovators who were not French.

\section{References}

1. Guinier D, Destrumelle N, Denue PO et al (2009) Technique of antroduodenectomy without ulcer excision as a safe alternative treatment for bleeding chronic duodenal ulcers. World J Surg 33:1010-1014

2. Fuerst EJ (1968) Gastroduodenostomy. An answer to the difficult duodenal stump. Am J Surg 115:287-290

3. Schein M, Gecelter GR (1990) Technical aids in surgery. Gastroduodenostomy for the "difficult" duodenum. S Afr J Surg 28:16-17

M. Schein $(\bowtie)$

Marshfield Clinic, 906 College Avenue West, Ladysmith,

WI 54848, USA

e-mail: Mschein1@mindspring.com 